TRABAJOS ORIGINALES

Rev Obstet Ginecol Venez. 2021; 81 (3): 209-225.

https://doi.org/10.51288/00810305

\title{
Factores de riesgo genético y diagnóstico prenatal
}

\author{
(D) Alisandra Morales de Machín, ${ }^{1}$ (D) Karelis Urdaneta, ${ }^{1}$ (D) Lisbeth Borjas, ${ }^{1}$ (D) Karile Méndez, ${ }^{1}$ \\ (D) Enrique Machín, ${ }^{1}$ (D) Ana Bracho. ${ }^{1}$
}

\begin{abstract}
RESUMEN
Objetivo: Identificar los factores de riesgo genético y su frecuencia en las pacientes estudiadas y describir los defectos congénitos diagnosticados en los fetos.

Métodos: La investigación se llevó a cabo en el Instituto de Investigaciones Genéticas de la Facultad de Medicina de la Universidad del Zulia. Maracaibo. Se estudiaron las pacientes referidas a la consulta de genética prenatal. Según los factores de riesgo genético identificados, se indicó: ecografía fetal, ecocardiografía fetal, triple marcador sérico materno, amniocentesis para obtención de células fetales para cariotipo fetal y análisis molecular.

Resultados: Fueron incluidas 568 pacientes. El 79,05\% de ellas presentó un factor de riesgo genético y el 20,95\% presentó dos o más. La edad materna avanzada fue el factor de riesgo genético más frecuente (40,85\%), seguido de antecedente familiar de primer grado con defecto congénito (35,21\%), anomalía ecográfica fetal (13,73\%), exposición a agentes potencialmente teratógenos (10,39\%), antecedente de aborto recurrente (7,04 \%), antecedente de muerte fetal $(4,22 \%)$, consanguinidad (1,93\%), y antecedente de muerte neonatal (1,76\%). Se diagnosticaron 101 fetos con defectos congénitos, una translocación balanceada, dos muertes fetales y 26 abortos espontáneos.

Conclusión: La identificación de los factores de riesgo genético sirvió como punto de partida para indicar los procedimientos de diagnóstico prenatal para valorar el estado de salud del feto y el diagnóstico de los anormales y ofrecer asesoramiento genético.
\end{abstract}

Palabras clave: Diagnóstico prenatal, Factores de riesgo, Asesoramiento genético.

\section{SUMMARY}

Objective: To identify genetic risk factors and frequency and to describe congenital defects of the fetus.

Methods: The research was conducted at the Genetic Research Institute of the Faculty of Medicine. University of Zulia. Maracaibo. We studied patients who attend to the prenatal genetic clinic. According to the Genetic risk factors Identified, it indicated different prenatal diagnostic procedures: fetal echography, fetal echocardiography, triple maternal serum marker, amniocentesis for fetal karyotype and molecular analysis.

Results: We included 568 patients. $79.05 \%$ of the total showed only one genetic risk factor and the 20.95\% two or more. The advanced maternal age was the most frequent genetic risk factor found (40.85\%), followed by first-degree family history with a congenital defect (35.21\%), abnormal fetal echography (13.73\%), exposure to teratogenic agents (10.39\%), history of recurrent abortion (7.04\%), history of fetal death (4.22\%), consanguinity $(1.93 \%)$, and history of neonatal death $(1.76 \%)$. They were diagnosed 101 fetuses with congenital defects, one balanced translocation, two fetal deaths and 26 spontaneous abortions.

Conclusion: The genetic risk factors identification, served as a starting point to indicate prenatal diagnostic procedures allowed a health evaluation of the fetus and adequate genetic counseling.

Key words: Prenatal diagnosis, Risk factors, Genetic counseling.

${ }^{1}$ Instituto de Investigaciones Genéticas, Facultad de Medicina, Universidad del Zulia (LUZ). Maracaibo. Venezuela. Este trabajo fue financiado por el Consejo de Desarrollo Científico y Humanístico de LUZ (Proyecto CC $0395-02)$.

Forma de citar este artículo: Morales A, Urdaneta K, Borjas L, Méndez $\mathrm{K}$, Machín E, Bracho A. Factores de riesgo genético y diagnóstico prenatal. Rev Obstet Ginecol Venez. 2021; 81(3):209-225. https://doi. org/10.51288/00810305

\section{INTRODUCCIÓN}

En el campo de los defectos congénitos (DC), se consideran factores de riesgo genético, todas aquellas condiciones que incrementen la probabilidad de tener 
un hijo con algún DC (1). Estos son determinados por factores causales que operan previo al nacimiento, durante o después de la concepción; pueden ser genéticos, ambientales y mixtos (2). Se clasifican en aislados o únicos y en patrones de defectos múltiples $(3,4)$. El DC aislado puede tener o no una base genética y la nomenclatura utilizada ayuda a comprender los diferentes mecanismos que podrían estar implicados, se incluyen malformación, disrupción, deformación y displasia. Entre los DC múltiples están secuencia, síndrome y asociación (3).

En el $2 \%$ de los hijos de padres sanos con una evolución obstétrica correcta ocurren DC y en el resto, estos trastornos tienen lugar en un grupo de embarazos que se consideran de riesgo genético, tales como: anormalidades cromosómicas (AC), enfermedades mendelianas, multifactoriales que resultan de complejas interacciones entre ciertos factores medioambientales y genéticos, exposición a teratógenos. Además, otras complicaciones de la reproducción, entre ellas infecundidad, aborto espontáneo, muerte fetal, muerte neonatal, pueden tener una causa genética $(3,5)$.

La frecuencia global de DC reportado oscila entre el $4 \%$ y el $5 \%$ (4). Durante el periodo 19952008, el Estudio Colaborativo Latinoamericano de Malformaciones congénitas (ECLAMC), reportó una frecuencia de DC de 2,7 \%, la frecuencia reportada para Venezuela fue de 2,4\% (6); estas son las cifras más recientes reportadas en Venezuela.

Se ha reportado que en Europa y Estados Unidos de América (EE. UU.), entre el $25 \%$ y $30 \%$ de todas las muertes perinatales y el $25 \%$ de las muertes en el primer año de vida se deben a DC estructurales; el $20 \%$ entre 1 y 10 años y alrededor del 7,5\% entre $\operatorname{los} 10$ y los 15 años (3). Se estima que cada año 270000 recién nacidos fallecen en el mundo durante los primeros 28 días de vida debido a DC y son la segunda causa de mortalidad infantil en América del Sur (7).
Carrera y cols. (4), citan que según la Organización Mundial de la Salud (OMS), el término diagnóstico prenatal agrupa todas aquellas acciones diagnósticas encaminadas a descubrir durante el embarazo un DC, entendiendo por tal toda anomalía del desarrollo morfológico, estructural, funcional o molecular presente al nacer (aunque puede manifestarse más tarde), externa o interna, familiar o esporádica, hereditaria o no, única o múltiple (4).

La edad materna avanzada (EMA) es la indicación más común para ofrecer el diagnóstico prenatal citogenético, por la relación con un mayor riesgo de tener un niño con $\mathrm{AC}$, especialmente la trisomía $(\mathrm{T})$ 21 o síndrome Down, T18 o síndrome Edward, T13 o síndrome Patau, y de las aneuploidías 47,XXX y 47,XXY (3, 8-10). En la actualidad se utiliza formando parte del cribado bioquímico y ecográfico, con el empleo de marcadores serológicos y ecográficos de aneuploidías del primer trimestre y su interrelación con marcadores del segundo trimestre (11).

Solo pueden considerarse métodos diagnósticos de las aneuploidías aquellos de estudio directo (cariotipo en vellosidades coriales, líquido amniótico o tejidos fetales) o indirecto de los cromosomas fetales como hibridación in situ fluorescente (FISH), y la reacción en cadena de la polimerasa cuantitativa y fluorescente. Todos ellos requieren de una técnica invasiva que conlleva un riesgo de pérdida fetal no deseada, de alrededor del $1 \%$ (4).

El objetivo de este trabajo fue identificar los factores de riesgo genético y su frecuencia en las pacientes estudiadas y describir los defectos congénitos diagnosticados en los fetos.

\section{MÉTODOS}

Se incluyen las pacientes que fueron estudiadas y atendidas en la consulta de diagnóstico prenatal del Instituto de Investigaciones Genéticas de la Facultad 
de Medicina de la Universidad del Zulia (IIG-LUZ), en el lapso comprendido entre enero de 1997 y febrero de 2006.

A cada una se le realizó historia clínica genética que incluyó edad de los progenitores, fecha de última menstruación, edad gestacional en la que fueron referidas (agrupando a las pacientes en el primer trimestre: <14 semanas de gestación, segundo trimestre: entre las 14 y 28 semanas y tercer trimestre: $>28$ semanas de gestación (12); motivo de consulta, antecedentes personales y familiares, evolución del embarazo. Se realizó genealogía de al menos tres generaciones y fue aplicado un consentimiento informado a la paciente y/o a su pareja; asimismo, el trabajo fue aprobado por el comité de bioética del IIGLUZ.

Los factores de riesgo genético fueron identificados a través del motivo de consulta y/o los antecedentes personales y familiares. Fueron considerados como tales: la EMA en las pacientes que tenían $\geq 35$ años de edad, antecedente de familiar de primer grado con DC en el cual se incluyó antecedente de AC en hijo, progenitor y hermano del progenitor, de enfermedad mendeliana, de defecto del tubo neural, y de cardiopatía congénita: considerando como tal a toda malformación estructural resultante de la morfogénesis del corazón y de los grandes vasos intratorácicos (11); anomalía ecográfica fetal en el embarazo actual: incluyó tanto marcadores ecográficos y defectos estructurales fetales mayores, exposición a teratógenos (fármacos, sustancias químicas, radiaciones, hipertermia, enfermedades infecciosas, exposición a vacunas y desequilibrio metabólico materno), antecedente de aborto recurrente: considerando aborto recurrente a dos o más abortos espontáneos en la paciente (13), antecedente de muerte fetal no estudiado: considerando aquellos fetos con muerte intrauterina con edad gestacional $\geq 20$ semanas de gestación (14), consanguinidad en las parejas: que describe el matrimonio entre familiares consanguíneos que tengan al menos un antepasado común no más remoto que un tatarabuelo (3); antecedente de muerte neonatal: considerando las muertes ocurridas desde el nacimiento y 27 días de vida posnatal (15).

Se realizó asesoramiento genético prediagnóstico prenatal, mediante el cual se manejó la información acerca de las ventajas, limitaciones, y complicaciones de los procedimientos a utilizar, los cuales fueron programados de acuerdo a sus indicaciones y a la edad gestacional.

Se indicó al menos una ecografía fetal, entre las 1234 semanas de gestación y fue realizada con ecógrafo, marca Toshiba y transductores convex de 3,5 y $5 \mathrm{MHz}$.

Se indicó ecocardiograma fetal en aquellas gestantes que tenían feto con anormalidad cromosómica, defecto estructural fetal, anomalías del ritmo cardiaco fetal, no visualización correcta de los cortes básicos del corazón, translucencia nucal aumentada (mayor que un percentil 95), retraso del crecimiento intrauterino (RCIU), polihidramnios y oligohidramnios, en gestantes con cardiopatía congénita, antecedentes de cardiopatía congénita y/o exposición a teratógenos en el primer trimestre (11). Esta evaluación fue realizada por un cardiólogo infantil, ecocardiografista fetal quien utilizó un ecocardiógrafo marca Advanced Technology Laboratories $^{\circledR}$, modelo Ultramark 9, con transductores convex 3,5 MHz y sectoriales de 3,5 y $5 \mathrm{MHz}$, entre las 18 semanas y el término de la gestación y entre los 7 a 15 días posterior al nacimiento.

Para el triple marcador sérico materno, se obtuvo suero materno entre 15 y 20 semanas de gestación. Se determinaron las concentraciones de alfafetoproteína, fracción beta libre de la gonadotrofina coriónica humana y estriol no conjugado. Los valores absolutos del laboratorio fueron obtenidos en nanogramos por decilitro (ng/dL) para AFP y uE3 y en unidad internacional por mililitro $(\mathrm{IU} / \mathrm{mL})$ para $(\beta-\mathrm{hCG}) \mathrm{y}$ 
se correlacionaron con los múltiplos de la mediana (MoM) establecidos previamente entre las 15 y 20 semanas de gestación.

La amniocentesis se indicó en casos de edad materna avanzada, antecedente de anormalidad cromosómica, historia familiar de un DC que puede ser diagnosticado mediante análisis bioquímico y del ácido desoxirribonucleíco (ADN), antecedente familiar de una enfermedad con herencia autosómica recesiva, autosómica dominante, ligada al cromosoma $\mathrm{X}$ dominante $\mathrm{y}$ ligada al cromosoma $\mathrm{X}$ recesiva, marcadores bioquímicos y ecográficos anormales de $\mathrm{AC}(1)$.

La amniocentesis la realizó un ginecoobstetra, entre las 15 y 18 semanas de gestación. Se hizo bajo monitorización ecográfica, utilizando aguja raquídea calibre 22 × $3 \frac{1}{1} 2$. Se extrajo a razón de un cc de líquido amniótico por semana de edad gestacional. Según el caso, se realizó análisis cromosómico mediante el cultivo de células fetales del líquido amniótico o de material de aborto, de acuerdo a técnicas convencionales (16) y de coloración con tripsina giemsa y un nivel de resolución mínimo de 400 bandas. Los cariotipos fueron interpretados usando la recomendación del Sistema Internacional de Nomenclatura Citogenética Humana (17); o se realizó extracción de ADN directo o posterior a cultivo para análisis molecular (18).

Cuando no se realizó el diagnóstico antes del parto, se continuó la evaluación posnatal o posmorten a través del examen genético clínico, estudios anatomopatológicos, citogenéticos, de ADN o de radioimagen de acuerdo con cada caso.

Se generó una base de datos a través del programa de cómputo Microsoft Excel donde fue analizada la data. Los resultados obtenidos fueron expresados en valores absolutos, porcentajes, media y desviación estándar.

\section{RESULTADOS}

Se estudiaron 568 pacientes, el 24,65\%, el 70,60\% y el 4,65\% consultaron durante el primer trimestre, segundo trimestre y tercer trimestre de la gestación respectivamente, con edades comprendidas entre $13 \mathrm{y}$ 50 años, con una media de 31,85 años $\pm 7,90$. La edad gestacional en la que fueron referidas estuvo entre las 5 y 34 semanas, con una media de $16,71 \pm 5,48$ semanas. En la tabla 1 se describe la distribución por edad materna y gestacional.

Tabla 1. Distribución de la edad materna y gestacional en pacientes con factores de riesgo genético

\begin{tabular}{|c|c|c|c|c|c|c|}
\hline \multirow[t]{2}{*}{$\begin{array}{l}\text { Edad materna } \\
\text { (años) }\end{array}$} & \multicolumn{2}{|c|}{$\begin{array}{l}\text { 1er Trimestre } \\
<14 \text { semana }\end{array}$} & \multicolumn{2}{|c|}{$\begin{array}{l}\text { 2do Trimestre } \\
14-28 \text { semanas }\end{array}$} & \multicolumn{2}{|c|}{$\begin{array}{l}\text { 3er Trimestre } \\
>28 \text { semanas }\end{array}$} \\
\hline & $\mathrm{n}$ & $\%$ & $\mathrm{n}$ & $\%$ & $\mathrm{n}$ & $\%$ \\
\hline$<35$ & 88 & 26,19 & 239 & 71,13 & 9 & 2,68 \\
\hline 35 y más & 52 & 22,41 & 162 & 69,83 & 18 & 7,76 \\
\hline
\end{tabular}

El factor de riesgo genético más frecuente fue la EMA en el 40,85\% de los casos, seguida del antecedente familiar de defecto congénito en el 35,21 \% (tabla 2).

Tabla 2. Distribución de los Factores de riesgo genético en las pacientes

\begin{tabular}{lcc}
\hline Factor de riesgo genético & $\mathrm{n}$ & $\%$ \\
\hline Edad Materna avanzada & 232 & 40,85 \\
$\begin{array}{l}\text { Antecedente de familiar de primer grado con } \\
\text { defecto congénito }\end{array}$ & 200 & 35,21 \\
Anormalidad ecográfica fetal & 78 & 13,73 \\
Exposición a agentes teratógenos & 59 & 10,39 \\
Antecedente de aborto recurrente & 40 & 7,04 \\
Antecedente de muerte fetal & 24 & 4,22 \\
Consanguinidad & 11 & 1,93 \\
Antecedente de muerte neonatal & 10 & 1,76 \\
\hline
\end{tabular}


La tabla 3 describe el antecedente familiar de defecto congénito. La tabla 4 describe el antecedente de anomalía cromosómica, en hijo (65,12 \%), en progenitores $(25,58 \%)$ y en hermano de progenitores $(9,30 \%)$. En la tabla 5 se resume el antecedente de enfermedades mendelianas y se describe el antecedente familiar de primer grado con: enfermedades ligadas al cromosoma $\mathrm{X}$ dominante, enfermedades ligadas al cromosoma $\mathrm{X}$ recesivas, enfermedades autosómicas recesivas y dominantes. En la tabla 6 se describen las anomalías ecográficas fetales y en la tabla 7 la exposición a teratógenos.

Tabla 3. Antecedente de familiar de primer grado con defecto congénito

\begin{tabular}{lccc}
\hline Defecto congénito & $\mathrm{n}$ & $\%$ & $\% \mathrm{n}=568$ \\
\hline Anormalidad cromosómica & 86 & 43 & 15,14 \\
Enfermedad mendeliana & 71 & 35,5 & 12,50 \\
Defecto de tubo neural & 24 & 12 & 4,23 \\
Cardiopatía congénita & 19 & 9,5 & 3,34 \\
\hline
\end{tabular}

Los resultados anormales según el procedimiento de diagnóstico prenatal utilizado son mostrados en la tabla 8. El triple marcador sérico materno fue sugerido en todos los casos, se realizó en 68, con anormalidad en siete casos (10,29\%): epidermolisis bulosa, anencefalia, T18, síndrome de Smith-LemliOpitz, uno en cada uno, dos con gastrosquisis, uno con cariotipo normal con RCIU y muerte fetal en paciente con preeclampsia, con inducción de parto a las 37 semanas de gestación.

La ecografía fetal se realizó en 355 casos con resultados anormales en 78 casos (21,97 \%). La ecocardiografía fetal se realizó en 115 casos, de ellos siete mostraron anormalidad estructural del corazón $(6,08 \%)$.
Tabla 4. Antecedente de familiar de primer grado con anormalidad cromosómica

\begin{tabular}{lcc}
\hline Anormalidad cromosómica & $\mathrm{n}$ & $\%$ \\
\hline Hijo n (\%) & 56 & 65,12 \\
Trisomía 21 libre & 41 & 47,67 \\
Trisomía 21 por translocación & 4 & 4,65 \\
Trisomía 21 mosaico & 2 & 2,33 \\
Trisomía 13 libre & 2 & 2,33 \\
Trisomía 13 por translocación & 1 & 1,16 \\
Deleción 13q- & 1 & 1,16 \\
Trisomía 18 libre & 2 & 2,33 \\
Trisomía 18 mosaico & 1 & 1,16 \\
Deleción 5 p- & 1 & 1,16 \\
Translocación 2q;3p & 1 & 1,16 \\
Progenitor & 22 & 25,58 \\
Translocación recíproca balanceada (8p;10p) & 1 & 1,16 \\
Translocación robertsoniana balanceada & 6 & 6,98 \\
Inversión 12q & 1 & 1,16 \\
Inserción 15p+ & 1 & 1,16 \\
Deleción 21p- & 1 & 1,16 \\
Trisomía 21 libre & 1 & 1,16 \\
Mosaicismo del cromosoma X & 11 & 12,79 \\
Hermano del progenitor & 8 & 9,30 \\
Translocación robertsoniana balanceada & 8 & 9,30 \\
\hline
\end{tabular}

Se realizó amniocentesis para cariotipo fetal en 280 gestantes, con resultados anormales en 16 casos $(5,71 \%)$. Se realizó análisis molecular en 50 casos, con resultados anormales en 15 casos (30\%). En la tabla 9 se describe cariotipo y ecografía fetal anormal y edad materna. Hubo 101 fetos con DC, dos muertes fetales, uno con translocación balanceada y 26 abortos espontáneos no estudiados. 
Tabla 5. Antecedente de familiar de primer grado con enfermedad mendeliana

\begin{tabular}{lcc}
\hline Enfermedad & $\mathrm{n}$ & $\%$ \\
\hline Herencia ligada al X recesiva n: 200 (16,50 \%) & 33 & 46,48 \\
Distrofia muscular de Duchenne & 24 & 33,8 \\
Hemofilia A & 6 & 8,45 \\
Hemofilia B & 3 & 4,23 \\
Herencia ligada al X dominante n: 200 (1\%) & 2 & 2,82 \\
Síndrome X frágil & 2 & 2,82 \\
Herencia autosómica recesiva n: 200 (11 \%) & 22 & 30,98 \\
Fibrosis Quística & 12 & 16,90 \\
Atrofia espinal & 2 & 2,82 \\
Enfermedad de Gaucher & 2 & 2,82 \\
Epidermólisis bulosa & 2 & 2,82 \\
Osteogénesis imperfecta tipo II & 2 & 2,82 \\
Enfermedad de Sanfilippo & 1 & 1,40 \\
Inmunodeficiencia combinada & 1 & 1,40 \\
Herencia autosómica dominante n: 200 (7 \%) & 14 & 19,72 \\
Acondroplasia & 5 & 7,04 \\
Síndrome de Crouzon & 2 & 2,82 \\
Esclerosis tuberosa & 2 & 2,82 \\
Distrofia miotónica & 2 & 2,82 \\
Enfermedad Charcot Marie Tooth & 2 & 2,82 \\
Síndrome de Apert & 1 & 1,40 \\
\hline
\end{tabular}

Tabla 7. Exposición a agentes potencialmente teratógenos

\begin{tabular}{lcc}
\hline Agente teratógeno & $\mathrm{n}$ & $\%$ \\
\hline Medicamentos & 16 & 27,12 \\
Radiaciones & 7 & 11,87 \\
Rubeola & 10 & 16,95 \\
Varicela & 8 & 13,56 \\
Toxoplasma & 1 & 1,69 \\
Vacunas & 7 & 11,87 \\
Diabetes & 6 & 10,17 \\
Hipertiroidismo & 2 & 3,39 \\
Hipotiroidismo & 1 & 1,69 \\
\hline
\end{tabular}

Tabla 6. Antecedente de familiar de primer grado anormalidad ecográfica fetal

\begin{tabular}{lcc}
\hline Diagnóstico ecográfico & $\mathrm{n}$ & $\%$ \\
\hline Ventriculomegalia o hidrocefalia & 13 & 16,67 \\
Malformación de Arnold Chiari & 5 & 6,41 \\
Complejo de Dandy Walker & 2 & 2,56 \\
Quiste del plexo coroideo & 2 & 2,56 \\
Agenesia de cuerpo calloso - polihidramnios & 1 & 1,28 \\
Anencefalia & 8 & 10,26 \\
Acráneo & 3 & 3,85 \\
Espina bífida & 7 & 8,97 \\
Holoprosencefalia - polihidramnios & 2 & 2,56 \\
Retardo de crecimiento intrauterino & 4 & 5,13 \\
Hidrops fetal & 13 & 16,67 \\
Higroma quístico & 3 & 3,85 \\
Displasia esquelética & 6 & 7,69 \\
Riñón poliquístico & 5 & 6,41 \\
Gastrosquisis & 3 & 3,85 \\
Onfalocele & 1 & 1,28 \\
\hline
\end{tabular}

Tabla 8. Resultados anormales según el procedimiento de diagnóstico prenatal utilizado

\begin{tabular}{lccc}
\hline Procedimiento & $\mathrm{n}$ & \multicolumn{2}{c}{ Resultado anormal } \\
\hline & & $\mathrm{n}$ & $\%$ \\
Triple marcador sérico materno & 68 & 7 & 10,29 \\
Ecografía fetal & 355 & 78 & 21,97 \\
Ecocardiografía fetal & 115 & 7 & 6,08 \\
Cariotipo fetal & 280 & 16 & 5,71 \\
Análisis molecular fetal & 50 & 15 & 30 \\
\hline
\end{tabular}


Tabla 9. Cariotipo y ecografía fetal anormal y edad materna

\begin{tabular}{lcc}
\hline Cariotipo fetal & Ecografía fetal & Edad materna (años) \\
\hline $47, \mathrm{XY}+13$ & Holoprosencefalia - polihidramnios & 35 \\
$46, \mathrm{XX}+13$, rob(13;13)(q10;q10) & Agenesia cuerpo calloso - polihidramnios & 26 \\
$46, \mathrm{XY}+13$, rob(13;14)(q10;q10) & HF - HQ & 27 \\
$45, \mathrm{XY}, \mathrm{rob}(13 ; 14)(\mathrm{q} 10 ; \mathrm{q} 10)$ & ---- & 32 \\
$47, \mathrm{XY}+18$ & Onfalocele & 46 \\
$47, \mathrm{XX}+18$ & Braquicefalia - RCIU & 38 \\
$47, \mathrm{XY}+21$ & Braquicefalia - RCIU & 45 \\
$47, \mathrm{XX}+21$ & HF - HQ - CC & 35 \\
$48, \mathrm{XYY}+21$ & ----- & 35 \\
$68, \mathrm{XXX}$ & $\mathrm{RCIU}$ & 21 \\
$45, \mathrm{X}$ & HF - HQ - CC & 21 \\
$45, \mathrm{X}$ & $\mathrm{HF}$ - HQ & 22 \\
$45, \mathrm{X}$ & $\mathrm{HF}$ - HQ & 24 \\
$45, \mathrm{X}$ & $\mathrm{HF}$ - HQ & 27 \\
$45, \mathrm{X}$ & HF - HQ - CC & 27 \\
$45, \mathrm{X}$ & HF - HQ & 28 \\
\hline
\end{tabular}

HF: hidrops fetal; HQ: higroma quístico;

RCIU: Restricción de crecimiento intrauterino;

CC cardiopatía congénita

\section{DISCUSIÓN}

Con la identificación de los factores de riesgo genéticos en las pacientes estudiadas, fue posible establecer un adecuado diagnóstico prenatal y permitió conocer el estado de salud del feto, confirmando la presencia o la ausencia de un DC específico. El número de factores de riesgo genético y los problemas para controlar la variabilidad de las definiciones, de los métodos de diagnóstico prenatal y posnatal, y el periodo de observación, dificultaron las comparaciones y provocaron las variaciones.

En este trabajo, en el 79,05\% (449/568) de las pacientes se encontró un factor de riesgo genético y se diagnosticaron 83 fetos $(19,15 \%)$ con DC, una muerte fetal, y 14 abortos espontáneos no estudiados, el $20,95 \%$ (119/568) presentó más de un factor de riesgo genético y se diagnosticaron 18 fetos $(15,12 \%)$ con DC, un feto con translocación balanceada, una muerte fetal y 12 abortos espontáneos no estudiados.

La EMA fue el factor de riesgo genético más frecuente, con el 40,85\%, lo cual no difiere de lo publicado en otros trabajos $(8-10,19,20)$. Se diagnosticó un feto con doble aneuploidía $(48, \mathrm{XYY}+21)$, uno con esclerosis tuberosa y cinco abortos espontáneos. En las pacientes con EMA más otros factores de riesgo genéticos hubo 11 fetos con DC, ocho abortos espontáneos y una muerte fetal. 
Siguió en frecuencia el antecedente familiar de defecto congénito, con $35,21 \%$, se reportó el antecedente de anomalía cromosómica en $43 \%$ y en el grupo total con $15,14 \%$, similar a lo reportado por otros autores $(8,21)$.

Las anomalías cromosómicas se agrupan en: reordenamiento cromosómico, aneuploidía y poliploidía. El reordenamiento cromosómico altera la estructura de los cromosomas, tales como: duplicación, deleción, inversión y translocación (22).

En la aneuploidía, se agregan o se eliminan uno o más cromosomas, el mecanismo implicado más frecuente es la no disyunción, durante la meiosis o la mitosis. Las células somáticas de los seres humanos normalmente poseen $2 \mathrm{n}=46$ cromosomas, donde $\mathrm{n}$ se refiere al número haploide de cromosomas. Los individuos con monosomía poseen 45 cromosomas, es decir es la pérdida de un cromosoma, representado como $2 \mathrm{n}-1$. Trisomía es la ganancia de un cromosoma, es decir, existen tres copias homólogas de un cromosoma, y es representado como $2 \mathrm{n}+1$ y posee 47 cromosomas. Tetrasomía es la ganancia de dos cromosomas homólogos; por tanto, habrá cuatro copias homólogas de un cromosoma determinado, es representado como $2 \mathrm{n}+2$ y posee 48 cromosomas. Puede producirse más de una aneuploidía en el mismo individuo. Un individuo que posee una copia adicional de dos cromosomas diferentes (no homólogos) se denomina trisómico doble y se representa como $2 n+1+1$ (22).

La aneuploidia altera la dosis de algunos genes, y las concentraciones de los productos génicos causan efectos fenotípicos intensos que dan por resultado el aborto espontáneo, alrededor del $2 \%$ de todos los fetos con anormalidad cromosómica sobreviven al nacimiento. Una excepción en la relación entre el número de genes y la dosis de proteína es la que concierne a los genes del cromosoma $\mathrm{X}$ de los mamíferos. Los cromosomas Xadicionales se inactivan
(22). La aneuploidía de los cromosomas sexuales es la más común observada, con una incidencia global de uno de cada 400-500 nacimientos. La no disyunción paterna en el $80 \%$ de los casos es el origen predominante de la monosomía $45 \mathrm{X}$ o síndrome de Turner y es la constitución cromosómica en el $50 \%$ de los casos. La incidencia es de uno cada 4000 nacidos vivos (NV) de sexo femenino. Presente en alrededor del $1 \%-2 \%$ de todos los embriones $(1,3)$.

La mayoría de las aneuploidías autosómicas terminan en aborto espontáneo. Las que afectan a un cromosoma completo, que son compatibles con la vida posnatal, son la T21, T18 y T13, estas cursan con retraso del crecimiento, retraso mental y múltiples DC. Cada una de ellas tiene un fenotipo diferenciable y están determinadas por la dosis extra de los genes presentes en el cromosoma adicional. La más común es la T21 y es la principal causa genética de retraso mental. Tiene una incidencia de uno de cada 800 NV y varía con la edad materna (1). La incidencia reportada en Venezuela es de 1,49 x $1000 \mathrm{NV}$ (23).

Alrededor del $92 \%$ posee tres copias completas del cromosoma 21 y se conoce como T21 primaria o libre, en el $90 \%$ de los casos la no disyunción ocurre en la madre, más frecuente en la meiosis I. El $4 \%$ tiene una translocación que puede ser de novo o heredada, ocurre con mayor frecuencia entre los cromosomas 14 y 21(22).

En la poliploidía se agregan uno o más conjuntos completos de cromosomas. Las células poliploides contienen múltiplos del número haploide de cromosomas, como 3n: 69 (triploidía) y puede estar causada por un fallo en la maduración de la división meiótica en un óvulo o en un espermatozoide que conduce, a la retención de un cuerpo polar o a la formación de un espermatozoide diploide. También por la fertilización de un óvulo por dos espermatozoides. Se han descrito pocos nacidos vivos triploides, y 
todos mueren al poco tiempo del nacimiento $(3,22)$. La no disyunción en la división mitótica produce mosaicismo, regiones de tejido que presentan diferentes constituciones cromosómicas (22).

En esta investigación, no se registró recurrencia en las pacientes que consultaron por antecedente de anomalía cromosómica en hijo. En el asesoramiento genético, se debe informar que el riesgo de recurrencia (RR) en cada embarazo para trisomía autosómica en mujeres quienes han tenido hijo con trisomía libre es alrededor de $1 \%(1)$.

En aquellas en quienes un integrante de la pareja tuvo cariotipo anormal, se diagnosticó un feto con cariotipo $69, \mathrm{XXX}$ y uno con cariotipo $46, \mathrm{XY},+13$, rob $(13 ; 14)(q 10, q 10)$, ambos con anormalidad ecográfica fetal, un feto portador de la translocación 13;14 con cariotipo 45,XY,rob(13;14)(q10,q10), y siete abortos espontáneos, en cinco de ellos además EMA.

En las parejas con translocación robertsoniana balanceada, el RR teórico de la T13 y de la T21 es de $1 / 3$. Sin embargo, en estudios poblacionales el RR empírico en la T13 es inferior al $2 \%$ y en la T21, cuando el portador de la translocación es femenino, tiene un riesgo entre el $10 \%$ y el $15 \%$ de tener un niño con T21, mientras que para los portadores masculinos el riesgo es del $1 \%$ al $3 \%$; además se les debe informar la importancia de identificar dicho reordenamiento balanceado en otros miembros de la familia $(1,3)$.

Se ha reportado que no es clara la importancia de los mosaicismos de cromosoma sexual para establecer el riesgo genético individual en la descendencia, por lo cual, se dificulta el asesoramiento genético a la hora de valorar su repercusión sobre el desarrollo de AC y su relevancia clínica (24).

Vol. 81, $\mathrm{N}^{\mathrm{o}} 3$, septiembre 2021.
El antecedente de enfermedades mendelianas, se reportó con frecuencia de $35,5 \%$ y en el grupo total de $12,5 \%$ por encima de lo reportado por otros autores $(6,8,19)$, hecho que se puede atribuir a la disparidad de criterios de selección de la población de riesgo. Todas las gestantes tenían historia genética previa en el IIG-LUZ, el cual es centro de referencia y de diagnóstico de enfermedades mendelianas a nivel regional, también por la inclusión de un protocolo específico para diagnóstico prenatal molecular de enfermedades mendelianas durante los años incluidos en esta investigación.

Las enfermedades mendelianas son producidas por mutaciones que afectan a un solo gen. Aunque son numerosas y, como grupo, constituyen una parte importante dentro de los DC, la frecuencia de cada una, de forma individual, suele ser baja (11).

En este trabajo se reportó para enfermedad ligada al cromosoma $\mathrm{X}$ recesivo una frecuencia de $46,48 \%$ y en el grupo de antecedente familiar de defecto congénito de $16,5 \%$. La enfermedad ligada al cromosoma $\mathrm{X}$ dominante tuvo una frecuencia de $2,82 \%$ y $1 \%$; la frecuencia de enfermedad autosómica recesiva fue $30,98 \%$ y $11 \%$, y para la enfermedad autosómica dominante fue $19,72 \%$ y $7 \%$ respectivamente.

Las técnicas de genética molecular y análisis bioquímico permiten el estudio de algunas enfermedades mendelianas y se pueden aplicar cuando hay un diagnóstico específico, porque existe antecedente familiar o por la sospecha clínica de una enfermedad concreta. Cada enfermedad tiene sus características propias y habitualmente existen laboratorios de referencia dedicados a su estudio y especializados en algunas de las más raras (11).

Es posible la detección directa para las múltiples enfermedades en las que se conoce la mutación. Para 
poder aplicar este análisis al diagnóstico prenatal, es imprescindible conocer la mutación responsable de la misma en la familia objeto del estudio. Si no se ha identificado en el gen la mutación o las mutaciones causantes de la enfermedad, se puede utilizar el análisis indirecto y deducir la presencia de la mutación, sobre la base del estudio de la segregación familiar de polimorfismos presentes en el ADN, se establecen y analizan diversas zonas polimórficas estrechamente relacionadas con el gen que contiene la mutación, que están físicamente muy cercanas o forman parte del gen, independientes de la naturaleza de la mutación responsable de la enfermedad. Con el análisis molecular de varios de estos marcadores en individuos sanos y enfermos de una familia, se pueden establecer los marcadores asociados a la enfermedad, se realiza la construcción de los haplotipos de cada uno de sus integrantes, las diferencias detectadas por los polimorfismos entre dos regiones homólogas de un mismo par cromosómico permiten seguir en un árbol genealógico la herencia de cada uno de los miembros de dicho par, y permite identificar el cromosoma portador de la mutación, al compararlo con un familiar afectado, y utilizar este análisis para el estudio prenatal $(5,25-27)$.

En este trabajo se realizó diagnóstico prenatal molecular directo en 25 casos: 10 para distrofia muscular Duchenne, 12 para fibrosis quística, dos para atrofia espinal y uno para enfermedad de Gaucher y se realizó diagnóstico prenatal molecular indirecto en 23 casos: 14 para distrofia muscular Duchenne, seis para hemofilia A, y tres para hemofilia B. En 23 fetos se realizó diagnóstico posnatal.

Se reportó recurrencia en $28,16 \%(20 / 71)$ y en el grupo de antecedente familiar de defecto congénito, de $10 \%$ (20/200): siete fetos afectados con distrofia muscular Duchenne, dos con hemofilia A, cuatro con fibrosis quística, dos con epidermolisis bulosa, dos con atrofia espinal, uno con enfermedad de Sanfilippo, uno con inmunodeficiencia combinada severa y uno con acondroplasia. De ellos, hubo cuatro pacientes con EMA, en uno EMA y consaguinidad parental y en uno, solamente consanguinidad parental. Además se presentó una muerte fetal en una paciente con distrofia miotónica, un aborto espontáneo en paciente con enfermedad de Gaucher y consanguinidad parental y un aborto espontáneo en paciente con antecedente de hijo con acondroplasia.

En estos casos el RR oscila entre $25 \%$ en cada embarazo para enfermedad autosómica recesiva y $50 \%$ para enfermedad autosómica dominante. En enfermedad ligada al cromosoma $\mathrm{X}$ dominante, todas las hijas de los hombres afectados con parejas normales son afectadas y todos sus hijos son normales, y en las mujeres afectadas con parejas normales, los hijos y las hijas presentan un riesgo de $50 \%$ de estar afectados. En enfermedad ligada al cromosoma $\mathrm{X}$ recesivo, en pareja formada por mujer portadora y hombre normal el RR es de $50 \%$ para los hijos (1).

La frecuencia del antecedente de defecto del tubo neural fue $12 \%$ en el grupo con antecedentes familiares de defecto congénito y en el grupo total $4,23 \%$, similar a lo reportado por otros autores $(6,8)$.

Morales y cols. (28), citan que los defectos del tubo neural, son los DC más frecuentes y severos del sistema nervioso central, resultan de un fallo en el desarrollo y cierre normal del tubo neural. Se clasifican según su localización, en espinales y craneales, los defectos espinales incluyen la espina bífida y sus variedades, oculta y quística (meningocele y mielomeningocele). $\mathrm{Y}$ los craneales (craneosquisis) que incluyen la anencefalia y el cefalocele (28). El cefalocele consiste en la protrusión de contenido intracraneal (meninges: meningocele craneal o meninges y tejido nervioso: encefalocele) (29). Según la presencia o no de tejido neural expuesto, el defecto del tubo neural se clasifica en abierto y cerrado (30). 
Se estima que la frecuencia, a nivel mundial, de defecto del tubo neural es de 1 a 10 por $1000 \mathrm{NV}$ (31) y de 0,5 a 2 por 1000 embarazos (32). Hernández y cols. (33), citan que, en Venezuela, la frecuencia de defecto del tubo neural varía de 0,5 a 2 por $1000 \mathrm{NV}$ y a nivel mundial representan del $20 \%$ al $45 \%$ de los DC reportados en las pérdidas gestacionales y en la mortalidad peri- y posnatal, y en productos de abortos espontáneos se presentan entre 3,6 \% y 9,09\% de los casos (33). La mayoría de los defectos del tubo neural ocurren de forma aislada, su patrón de herencia es multifactorial y el RR en cada embarazo varía entre $3 \%$ y $6 \%$. Está influenciado por el sexo, el número de individuos afectados y la gravedad del defecto (1).

En este trabajo se reportó un feto masculino con anencefalia y anomalía ecográfica fetal, con recurrencia de $4,16 \%(1 / 24)$ y un aborto espontáneo de paciente con mosaicismo del cromosoma X. El asesoramiento genético de estas parejas estuvo dirigido hacia la vigilancia en los embarazos sucesivos y la indicación de ácido fólico a una dosis de $4 \mathrm{mg}$ diarios, durante el periodo periconcepcional.

La frecuencia del antecedente de cardiopatía congénita fue de $9,5 \%$ y en el grupo total de $3,35 \%$, lo cual difiere a lo publicado en otros trabajos (8). Las cardiopatías congénitas constituyen el conjunto de DC graves más frecuentes en abortos espontáneos, la presencia es de $20-25 / 1000$ casos. Afecta a $0,5 \%-1 \%$ de los recién nacidos, en niños que sobreviven al año de vida es de 5/1000, están presentes en el $20 \%$ de las muertes neonatales y en el $50 \%$ de la mortalidad infantil debido a DC. El diagnóstico de una cardiopatía congénita en la vida fetal implica una mortalidad global de $25 \%$ $35 \%$, un $60 \%$ durante el primer año de vida. Más del $90 \%$ de cardiopatías congénitas aparece en fetos sin antecedente. En $25 \%$ - 40 \% se presentan asociadas a otros DC, el resto aislados y, en estos, el mecanismo de transmisión más frecuente es multifactorial (11).
Desde el punto de vista de la ecografía prenatal, las cardiopatías congénitas se dividen en anomalías de los tractos de entrada (válvulas atrioventriculares) y de los tractos de salida (grandes arterias). En las cardiopatías congénitas que alteran el corte de las cuatro cámaras se incluyen: canal atrioventricular común, comunicación interventricular, síndrome del corazón izquierdo hipoplásico, coartación aórtica, corazón derecho hipoplásico, anomalías de tipo displásico de la válvula tricúspide (anomalía de Ebstein), ventrículo único de doble entrada. En las cardiopatías congénitas que alteran los cortes de los grandes vasos se incluyen: tetralogía de Fallot, transposición completa de grandes arterias, ventrículo derecho doble salida y tronco común arterioso (11).

El canal atrioventricular común es la cardiopatía congénita más frecuente diagnosticada en útero, $15 \%-20 \%$ del total de cardiopatías congénitas; al nacer corresponde al $4 \%-5 \%$ de todas ellas y a 1/1500 recién nacidos. Es un defecto de fusión de los cojinetes subendocárdicos. Se distinguen dos tipos: canal completo y canal parcial o incompleto. El síndrome del corazón izquierdo hipoplásico, se caracteriza por hipodesarrollo del ventrículo izquierdo y su tracto de salida, la aorta. Es el $17 \%$ de las cardiopatías congénitas diagnosticadas en útero y el $3 \%$ al nacimiento. La comunicación interventricular es un defecto en el tabique interventricular; constituye el $5 \%-7 \%$ de las cardiopatías congénitas diagnosticadas en útero, es la más frecuente detectada en la infancia y diagnosticada al nacimiento: $25 \%$-30 \% del total de las cardiopatías congénitas; afecta a 1/250-300 recién nacidos (11).

La tetralogía de Fallot es la cardiopatía congénita conotruncal más frecuente; representa el $3 \%-5 \%$ de las cardiopatías congénitas diagnosticadas en útero. Su incidencia al nacimiento es del $9 \%-10 \%$ del total de las cardiopatías congénitas. Afecta a 1/1000 recién nacidos. Consiste en una comunicación interventricular 
(CIV), mal alineamiento de la aorta con desplazamiento anterior y cabalgamiento en el septo infundibular, estenosis pulmonar e hipertrofia del ventrículo derecho. En útero se denomina "complejo CIV + aorta cabalgada", raramente existe hipertrofia del ventrículo derecho y la estenosis pulmonar suele ser evolutiva durante la gestación. En el $10 \%$ de los casos se asocia a la microdeleción en la región q11 del cromosoma 22 (22q11), que requerirá estudio FISH. El pronóstico de la tetralogía de Fallot diagnosticada en útero es malo, con cifras de supervivencia globales del $20 \%$ $30 \%(11)$.

Los tumores cardiacos en el feto representan el 2,8 \% de las cardiopatías congénitas diagnosticadas en útero. Se han descrito: rabdomioma, teratoma, hemangioma atrial,fibromayhamartoma.Elrabdomiomarepresentael $86 \%$. Se asocia a esclerosis tuberosa en un $95 \%$ $100 \%$ en los casos de tumores múltiples. La esclerosis tuberosa es una enfermedad autosómica dominante, existen casos de mutaciones nuevas, cursa con fenotipo variable que se caracteriza por la presencia de tumoraciones de bajo grado de malignidad en múltiples órganos. La principal causa de mortalidad posnatal se relaciona con alteraciones del sistema nervioso central, que ocurren en más del $80 \%$ de casos (11).

En este trabajo se reportó un feto con comunicación interventricular, de paciente con tetralogía de Fallot, con recurrencia de 5,26\% (1/19). En este caso está indicado en ambos realizar FISH en busca de la microdeleción 22q11. Se diagnosticó en pacientes sin antecedentes de cardiopatía congénita: una comunicación interventricular en displasia esquelética tipo Langer Saldino; dos canal atrioventricular común: una en feto con T21 y otra en displasia esquelética tipo Majewsky, dos fetos con síndrome del corazón izquierdo hipoplásico y 45,X; y un feto con múltiples tumores intracardiacos y en etapa posnatal se confirmó esclerosis tuberosa de novo.
La anomalía ecográfica fetal se reportó con una frecuencia de $13,73 \%$, similar a otros autores (10, 20,34). Se realizó ecografía del primer trimestre en el $14,93 \%(53 / 355)$ de los casos, del segundo trimestre, en el $80 \%(284 / 355)$, y del tercer trimestre en el $5,07 \%(18 / 355)$.

Son marcadores ecográficos de sospecha de anormalidades cromosómicas: la translucencia nucal aumentada, los quistes del cordón umbilical, la anomalía placentaria, la alteración de la frecuencia cardíaca fetal, la ausencia del hueso nasal, el RCIU simétrico, el incremento de resistencia en la arteria umbilical y del índice de pulsatilidad del conducto venoso, el foco hiperecogénico intracardiaco, la arteria umbilical única, la ectasia piélica, el quiste de plexo coroideo, el pliegue nucal, el acortamiento de los huesos largos, la hipoplasia de la segunda falange del quinto dedo de la mano, la separación entre el primer y el segundo ortejo, el ángulo ilíaco aumentado, la braquicefalia, la megacisterna magna, la ventriculomegalia, la hiperecogenicidad intestinal (4).

Los defectos estructurales constituyen el $3 \%$ del total de los nacimientos y el $60 \%$ sobre el total de los DC. El diagnóstico por ecografía de uno o varios defectos estructurales debe ir seguido de interpretación patogénica, y de mejor caracterización por otras técnicas diagnósticas (4).

La mayoría de los defectos del sistema nervioso central fetal pueden detectarse en útero, también DC de cara: (hiper- e hipotelorismo, microftalmia, anoftalmía, cataratas, dacriocistocele, tumores faciales, macroglosia, labio y paladar hendido, micrognatia, otocefalia, arrinia, prosboscis); cuello: (higroma quístico, bocio, teratoma); tórax: (hipoplasia pulmonar, hernia diafragmática, malformación adenomatosa quística pulmonar, enfisema lobar, derrame pleural, quistes broncogénicos); del aparato digestivo: (atresia 
esofágica y duodenal, atresia y estenosis yeyuno-ileal, íleo y peritonitis meconial, duplicación intestinal, atresia de colon y ano-rectal, DC hepatobiliares, ascitis, persistencia de la vena umbilical derecha); de pared abdominal (gastrosquisis, onfalocele, extrofia vesical y cloacal); urinarios: (agenesia y disgenesia renal, pielectasia e hidronefrosis, megavejiga, megauréter, riñón ectópico, duplicación renal, tumores renales); DC esqueléticos, hidrops fetal (29).

Los defectos del sistema nervioso central se clasifican en: holoprosencefalia, displasia septoóptica, agenesia del cuerpo calloso, defectos de la fosa posterior (complejo de Dandy Walker), defectos de la proliferación (microcefalia), defectos en la migración de neuronas: lisencefalia, megalencefalia unilateral y defectos del tubo neural (11).

El complejo de Dandy Walker se refiere a la asociación entre ventriculomegalia, cisterna magna aumentada de tamaño y defecto en el vermis cerebeloso. Su prevalencia se estima en $1 / 30000$ nacimientos y se encuentra presente en el $12 \%$ de todos los casos de ventriculomegalia congénita. Se ha reportado en los síndromes Meckel y Warburg, en AC y en exposición a teratógenos (11, $31)$.

Para el diagnóstico ecográfico de espina bífida existen signos directos, que resultan del defecto vertebral, de la disrupción de los tejidos blandos y de la presencia del saco herniario, e indirectos que se manifiestan a nivel de la calota fetal y que responden al desplazamiento del vermis cerebeloso, cuarto ventrículo y médula oblonga a través del foramen magnum, conocido como síndrome de Arnold Chiari II. Se observan el signo del limón, de la banana, la obliteración de la cisterna magna y ventriculomegalia (29).

Los hallazgos ecográficos detectados en este trabajo fueron: 13 fetos con ventriculomegalia, cinco con malformación de Arnold Chiari, dos con complejo de Dandy Walker, dos con quiste de plexo coroideo, uno con agenesia de cuerpo calloso (con T13), siete con espina bífida, ocho con anencefalia, tres acráneos, y dos con holoprocencefalia (uno con T13 de paciente con EMA). Cuatro fetos con RCIU de estos, dos con braquicefalia (uno con T18 y otro con T21 ambos de pacientes con EMA), uno con cariotipo $69, \mathrm{XXX}$ de paciente con $\mathrm{AC}$, y una muerte fetal con cariotipo 46,XY de paciente con EMA y preeclampsia; 13 fetos con hidrops fetal: seis con cariotipo 45, X, uno con T21 de paciente con EMA y uno con T13 de paciente con $\mathrm{AC}$, (uno con tronco común arterioso, una displasia esquelética tipo Majewski, uno con atresia yeyunal e ileo meconial diagnosticados posnatalmente) y dos fetos con etiología desconocida. Tres con higroma quístico. Cinco con displasia esquelética: (uno tipo Langer Saldino, dos acondroplasia, uno con síndrome de Smith-Lemli-Opitz y uno sin diagnóstico etiológico). Cinco con riñón poliquístico. Tres con gastrosquisis y uno con onfalocele y T18 de paciente con EMA.

Con exposición a teratógenos, se reportó frecuencia de $10,39 \%$, similar a lo reportado por otros autores (34). Se denomina teratógeno un agente que puede causar un DC al interferir con el desarrollo normal del embrión o del feto, su efecto depende de la dosis y del momento de su administración durante el embarazo, así como de la susceptibilidad tanto de la madre como del feto (3).

En este trabajo se reportó un feto macrosómico (peso y talla al nacer $4950 \mathrm{~g}$ y $54 \mathrm{~cm}$ ), en una paciente de 41 años, con diabetes gestacional. La madre diabética con mal control de la glucosa le transfiere a su hijo, a través de la placenta, gran cantidad de glucosa, lípidos y aminoácidos, que estimulan el páncreas fetal ocasionando hiperplasia de las células $\beta$ e hiperinsulinismo, responsable de la mayoría de los DC que se observan en estos fetos, especialmente la 
macrosomía y la hipoglicemia. Los DC frecuentes son regresión caudal, cardiopatía congénita y defectos del sistema nervioso central (11).

El antecedente de aborto recurrente fue de 7,04\%, diferente a lo reportado por otros autores $(8,34)$. La incidencia de aborto recurrente oscila entre el $0,5 \%$ al $5 \%$. Se han planteado muchas causas para aborto recurrente, pero solo las alteraciones anatómicas del útero y las causas genéticas parecen ser indiscutibles. Otras pueden estar sujetas a controversia, como son las alteraciones autoinmunes tipo lupus eritematoso, la insuficiencia luteínica, los ovarios poliquísticos, la alteración tiroidea, las enfermedades sistémicas y agresiones extrínsecas (35).

Morales y cols. (36) citan que, en aborto recurrente, se han reportado AC en el $29 \%-60 \%$ del material de aborto; sin embargo, la mayoría de estas son alteraciones numéricas, que probablemente ocurrieron de novo, y las AC estructurales, se presentan con prevalencia que oscila entre $3 \%$ y $10,8 \%$ (36).

En este trabajo, en 12/40 (30 \%) casos ya habían sido identificadas $\mathrm{AC}$ en alguno de los progenitores, en siete $(17,5 \%)$ con mosaicismo Turner con bajo porcentaje de células monosómicas para el cromosoma $\mathrm{X}$, y en cinco $(12,5 \%)$ con translocación balanceada; en dos casos anormalidad uterina, en uno problemas hormonales, en uno factor masculino y en 24 con factor etiológico no identificado. En 16 casos ocurrió aborto espontáneo: dos con $\mathrm{AC}$ en la madre, en ocho con EMA y, de ellos, tres con AC y EMA. El factor de riesgo genético consanguinidad se reportó con una frecuencia de $1,93 \%$.

Los genes mutados autosómicos recesivos se expresan cuando ocurre emparejamiento de dos personas que sean portadoras de un alelo mutado en el mismo locus y que un hijo de ambos herede los dos alelos de la enfermedad. Esta posibilidad aumenta si los progenitores están relacionados genéticamente entre sí. En los emparejamientos entre primos hermanos, el riesgo de que los descendientes tengan problemas (considerando no solo las enfermedades autosómicas recesivas, sino también los abortos espontáneos, las muertes neonatales y los DC) es del $3 \%-5 \%$, aproximadamente el doble del riesgo global del $2 \%-3 \%$ que presentan los hijos de parejas que no muestran consanguinidad (1).

En este trabajo se reportó consanguinidad y antecedente de enfermedad autosómica recesiva en cuatro parejas; dos con fibrosis quística, una con atrofia espinal y una con enfermedad de Gaucher, resultando un feto afectado con fibrosis quística, uno con atrofia espinal, y un aborto espontáneo.

Loughrin y cols. (14) refieren que, la OMS define muerte fetal como la muerte previa a la expulsión o extracción completa de su madre de un producto de la concepción, independiente de la duración del embarazo. El periodo mínimo de gestación requerido en los EE. UU. para el registro de muerte fetal varía. En general, el periodo mínimo es de 20 semanas de gestación; en otros se incluyen todos los periodos de gestación o modifican la definición por peso o longitud fetal (14).

Según la edad gestacional o en su defecto el peso, la muerte fetal se clasifica en temprana, intermedia y tardía. La intermedia es la que ocurre entre la 20 y 27 semanas de gestación, con peso fetal entre 500 y 999 gramos. La muerte fetal tardía es la que ocurre a partir de las 28 semanas de gestación, con peso fetal de 1000 gramos o más (37).

La muerte fetal intermedia y tardía, ocurre en $1 \%$ de los embarazos y es responsable del $50 \%$ de toda la mortalidad perinatal. La muerte fetal se ha relacionado a: infarto y desprendimiento prematuro de placenta, anormalidad de cordón umbilical, hipertensión y 
diabetes materna, DC, infección fetal, gestación múltiple, y muerte fetal inexplicable (38).

Durante 2015-2017, la tasa de mortalidad fetal de EE.UU., fue de 6 por 1000 NV (39). En Venezuela, la cifra más reciente fue de 23,4 por $1000 \mathrm{NV}$ (40).

En este trabajo, se reportó un aborto espontáneo y en una paciente con antecedente de muerte fetal y anomalía ecográfica fetal de displasia esquelética, se diagnosticó en etapa posnatal un feto con síndrome de Smith-Lemli-Opitz, quien falleció a los 17 días de edad.

El antecedente de muerte neonatal se reportó con una frecuencia de 1,76 \%. En EE.UU., la muerte neonatal está relacionada con DC graves, prematuridad, complicaciones obstétricas antes o durante el nacimiento, sepsis (15). La tasa de mortalidad neonatal global promedio en el año 2019, fue de 17/1000 NV (41). En este trabajo no se reportó recurrencia y hubo un aborto espontáneo.

Se puede concluir que la identificación de los factores de riesgo genético sirvió como punto de partida para indicar los procedimientos de diagnóstico prenatal para valorar el estado de salud del feto y el diagnóstico de las anomalías y para ofrecer asesoramiento genético.

\section{AGRADECIMIENTO:}

Este trabajo fue financiado por el Consejo de Desarrollo Científico y Humanístico (CONDES) de la Universidad del Zulia (Proyecto CC - 0395 - 02).

A Enrique Alejandro Machín Morales, por su gran aporte.

\section{REFERENCIAS}

1. Nussbaum RL, Mclnnes RR, Willard HF. Genética en medicina de Thompson \& Thompson. 7a ed. Madrid: Elsevier Masson; 2008.

2. Penchaszadeh V. Genética y salud pública. Bol of Sanit Panam [Internet]. 1993; 115(1): 1-11 [consultado noviembre 2020]. Disponible en: https://iris.paho. $\mathrm{org} / \mathrm{bitstream} / \mathrm{handle} / 10665.2 / 16327 / \mathrm{v} 115 \mathrm{n} 1 \mathrm{p} 1$. pdf? sequence $=1$ \&isAllowed $=\mathrm{y}$

3. Turnpenny P, Ellard S. Elementos de Genética Médica de Emery. 13a. ed. Madrid: Elsevier, SL; 2009.

4. Carrera J. Diagnóstico Prenatal: un concepto en evolución. En: Carrera J, Kurjak A, editores. Ecografía en diagnóstico prenatal. Colección de medicina materno-fetal. 1a. ed. Madrid: Elsevier Masson; 2008. p.3-146.

5. Goldberg J, Norton M. Técnicas diagnósticas prenatales. En: Harrison M, Evans M, Adzick S, Holzgreve W, editores. El paciente prenatal. Arte y ciencia de la terapia fetal. 3a ed. México DF: McGrawHill Interamericana; 2002. p.139-645.

6. Nazer J, Cifuentes L. Malformaciones congénitas en Chile y Latino América: Una visión epidemiológica del ECLAMC del período 1995-2008. Rev Med Chile. 2011; 139(1):72-78. http://dx.doi.org/10.4067/S003498872011000100010

7. World Health Organization [Internet]. Ginebra: Congenital anomalies; 2016. [consultado agosto 2021]. Disponible en: https://www.who.int/es/news-room/ fact-sheets//detail/congenitalanomalies

8. Prieto M, Molero A, Carrasquero N, Paz V, González $\mathrm{S}$, Pineda L, et al. Diagnóstico prenatal I: programa de diagnóstico prenatal de la Unidad de Genética de la Universidad del Zulia. Invest clín [Internet]. 1998 [consultado noviembre de 2020]; 39(2):97-116. Disponible en: https://produccioncientificaluz.org/ index.php/investigacion/article/view/28378/29091

9. Comas C, Echevarría M, Muñoz A, Rodríguez I, Carrera M, Serra B. 10 años de experiencia en diagnóstico prenatal invasivo en el Instituto Dexeus. Diagn Prenat. 2011; 22(4): 117-127. doi: 10.1016/j. diapre.2011.07.002

10. Alsius M, Solar A, Saez M, Bach C, Cabrero M, Borrell A, et al. Diagnóstico prenatal en la provincia de Girona en el período 1999-2009. Diagn Prenat. 2013; 24(3): 90-98. doi: 10.1016/j.diapre.2013.06.001 
11. Vendrell T, Sánchez M. Análisis genético y cariotipo fetal. Conceptos básicos. En: Gratacós E. Gómez R. Nicolaides K. Romero R. Cabero L, editores. Medicina fetal. Madrid: Médica Panamericana; 2007. p.69-615.

12. Grupo de trabajo de la Sociedad Española de Ginecología y Obstetricia, Guía de práctica clínica: Diagnóstico prenatal de los defectos congénitos. Cribado de anomalías cromosómicas. Diagn Prenat. 2013; 24(2): 57-72. doi: 10.1016/j.diapre.2012.06.013

13. Pokale J, Khadke P. Cytogenetic Studies of recurrent miscarriage. A review. ISRR. 2016; 4 (1): 1-18. doi:10.9734/ISRR/2016/23441

14. Loughrin H, Kirschbaum T. Muerte fetal intrauterina. En Iffi-Kaminetzky, editores. Obstetricia y perinatología. Principios y práctica. 3a. ed. Buenos Aires: Médica Panamericana SA; 1992. p.1144-1163.

15. Osterman MJ, Kochanek KD, MacDorman MF, Strobino DM, Guyer B. Annual summary of vital statistics: 2012-2013. Pediatrics. 2015; 135(6):11151125. doi: 10.1542/peds.2015-0434.

16. Carp H, Toder V, Aviram A, Daniely M, Mashiach S, Barkai G. Karyotype of the abortus in recurrent miscarriage. Fertil Steril. 2001; 75(4):678-682. doi: 10.1016/s0015-0282(00)01801-x.

17. Shaffer L, Tommerup N. An International System for human cytogenetic nomenclature. 4a ed. Basilea: Karger; 2005.

18. Old J. Fetal DNA analysis. En: Davies KE, editor. Human Genetics Diseases: A practical approach. 1a ed. Oxford: IRL Press, 1986. p1-17.

19. Hernández G, González N, Barrios A, Méndez L. Factores de riesgo genéticos y no genéticos en gestantes con diagnóstico prenatal. Mayabeque. 2010-2012. Rev Cubana Genet Comunit [Internet]. 2015 [consultado noviembre de 2020]; 9(3): 29-35. Disponible en: https://www.medigraphic.com/pdfs/revcubgencom/ cgc-2015/cgc153d.pdf

20. Becerra C, Serrano N. Diagnóstico prenatal de aneuploidía por amniocentesis. Experiencia de dos años de trabajo. Rev Colomb Obstet Ginecol. 1998; 49(3): 163-166. Disponible en: https://revista.fecolsog. org/index.php/rcog/article/download/1051/1192

21. Quintana J, Quiñones O, Méndez L, Lavista M, González C, Hernández G. Resultados del diagnóstico prenatal cromosómico en Ciudad Habana. Rev Cubana Obstet Ginecol [Internet]. 1999 [consultado noviembre de 2020]; 25(3):153-158. Disponible en: http://scielo. sld.cu/scielo.php?script=sci_arttext\&pid=S0138600X1999000300003
22. Pierce B. Genética. Un enfoque conceptual. 2a ed. Buenos Aires: Médica Panamericana; 2006.

23. Nazer J, Cifuentes L. Estudio epidemiológico global del Síndrome de Down. Rev Chil Pediatr. 2011; 82(2):105-112. http://dx.doi.org/10.4067/S037041062011000200004

24. Peschka B, Leygraaf J, Van der Ven K, Montag M, Schartmann B, Schubert R, et al. Type and frequency of chromosome aberrations in 781 couples undergoing intracytoplasmic sperm injection. Hum Reprod. 1999; 14(9):2257-2263. doi: 10.1093/humrep/14.9.2257.

25. Morales A, Borjas L, Zabala W, Álvarez F, Fernández E, Zambrano $\mathrm{M}$, et al. Diagnóstico prenatal molecular indirecto de Hemofilia A y B. Invest Clin [Internet]. 2008 [consultado noviembre de 2020]; 49(3); 289-297. Disponible en: $\quad$ http://ve.scielo.org/scielo.php?script=sci arttext\&pid=S0535-51332008000300002

26. Morales A, Delgado W, Borjas L, Hernández M, Zabala W, Solís E. Diagnóstico molecular in útero de Distrofia Muscular tipo Duchenne. Rev Obstet Ginecol Venez [Internet]. 2008 [consultado noviembre de 2020]; 68(4): 228-232. Disponible en: http://www.sogvzla. org.ve/sogvzla $20186 / \mathrm{cms} / \mathrm{svcobtenerpdfrevista.}$ php?id $=0000000018 \&$ tipo $=$ normal\&fila $=5$

27. Morales A, Delgado W, Borjas L, Méndez K, Zabala W, Solís E, et al. Diagnóstico prenatal molecular de Distrofia Muscular Duchenne. Rev Obstet Ginecol Venez [Internet]. 2017 [consultado noviembre de 2020]; 77(4):251-257. Disponible en: http://www.sogvzla. org.ve/sogvzla $20186 / \mathrm{cms} / \mathrm{svcobtenerpdfrevista.}$ php?id $=0000000087 \&$ tipo $=$ normal\&fila $=4$

28. Morales A, Méndez K, Solís E, Borjas L, Bracho A, Hernández $\mathrm{M}$, et al. Polimorfismo C677T del gen de la metilentetrahidrofolato reductasa en madres de niños afectados con defectos del tubo neural. Invest Clin [Internet]. 2015 [consultado noviembre de 2020]; 56(3): 284-295. Disponible en: $\quad$ http://ve.scielo.org/scielo.php?script=sci_ arttext\&pid=S0535-51332015000300006

29. Muñoz H, Hernández I, Nazaretian M, Henriquez G. Ecocardiografía fetal. En: Cafici D. Mejides A. Sepúlveda W, editores. Ultrasonografía en obstetricia y diagnóstico prenatal. Buenos Aires: Ediciones Journal; 2003. p.207-475.

30. Greene ND, Copp AJ. Development of the vertebrate central nervous system: formation of the neural tube. Prenat Diagn. 2009; 29(4):303-311. doi: 10.1002/ pd.2206. 
31. Au KS, Ashley-Koch A, Northrup H. Epidemiologic and genetic aspects of spina bifida and other neural tube defects. Dev Disabil Res Rev. 2010; 16(1):6-15. doi: 10.1002/ddrr.93.

32. Greene ND, Stanier P, Copp AJ. Genetics of human neural tube defects. Hum Mol Genet. 2009; 18(R2):R113-129. doi: 10.1093/hmg/ddp347.

33. Hernández M, Romero M, Morales A, Angarita M, Silva Ch, Delgado W, et al. Defectos del tubo neural en productos de abortos espontáneos. Rev Obstet Ginecol Venez [Internet]. 2009 [consultado noviembre de 2020]; 69(1):12-19. Disponible en: http://www.sogvzla. org.ve/sogvzla20186/cms/svcobtenerpdfrevista. php?id $=0000000017 \&$ tipo $=$ normal \&fila $=4$

34. Moreno $\mathrm{H}$, Valera $\mathrm{V}$, Bracho $\mathrm{A}$, Rodríguez $\mathrm{Z}$, Martínez $\mathrm{X}$, Herrera $\mathrm{M}$, et al. Atención genética perinatal primaria para la prevención de los defectos del nacimiento. Rev Obstet Ginecol Venez [Internet]. 1998 [consultado noviembre de 2020]; 58(4): 217-229. Disponible en: http://www.sogvzla. org.ve/sogvzla20186/cms/svcobtenerpdfrevista. php?id $=0000000060 \&$ tipo $=$ normal $\&$ fila $=2$

35. Parrilla J. Aborto recurrente, definiciones, incidencia y factores epidemiológicos. En: Pellicer A, Simón C, editores. Cuadernos de Medicina Reproductiva. Madrid: Medica Panamericana, 1997. p13-23.

36. Morales A, Bracho A, Urdaneta K, Machín E, Morales A. Translocación robertsoniana balanceada en parejas con aborto recurrente. Rev Obstet Ginecol Venez [Internet]. 2019 [consultado noviembre de 2020]; 79(1):29-36. Disponible en: http://www.sogvzla. org.ve/sogvzla20186/cms/svcobtenerpdfrevista. php?id $=0000000093 \&$ tipo $=$ normal $\&$ fila $=6$
37. Díaz A, Sarué E, Fescina R, Giacomini H, Díaz $\mathrm{J}$, Simini $\mathrm{F}$, et al. Estadística básica. Manual de autoinstrucción [Internet]. Montevideo: Centro Latino Americano de Perinatología y Desarrollo Humano. Organización Panamericana de la Salud. Organización Mundial de la Salud. 1992 [consultado noviembre de 2020]. Disponible en: http://www.clap.ops-oms.org/ publicaciones/clap1249.pdf

38. Genest D. Fetal death: maceration, autolisis and retention. En: Reed G, Claireaux A, Cockburn F, editores. Diseases of the fetus and newborn. Pathology, imaging, genetics and management. 2a ed. Londres: Chapman \& Hall Medical; 1995. p.269-274.

39. Pruitt SM, Hoyert DL, Anderson KN, Martin J, Waddell L, Duke C, et al. Racial and Ethnic Disparities in Fetal Deaths - United States, 2015-2017. MMWR Morb Mortal Wkly Rep. 2020; 69(37):1277-1282. doi: 10.15585/mmwr.mm6937a1.

40. Faneite P. Mortalidad materna y perinatal. Tendencias 1969-2004. Rev Obstet Ginecol Venez [Internet]. 2006 [consultado noviembre de 2020]; 66(2):75-79. Disponible en: http://www.sogvzla. org.ve/sogvzla $20186 / \mathrm{cms} / \mathrm{svcobtenerpdfrevista.}$ php?id $=0000000028 \&$ tipo $=$ normal \&fila $=5$

41. UNICEF [Internet]. Nueva York: Neonatal mortality; 2020. [consultado agosto 2021] Disponible en: https:// data.unicef.org/topic/child-survival/neonatal-mortality/

Recibido 16 de diciembre de 2020 Aprobado 10 de marzo de 2021 